THE RING 31, 2 (2009) DOI 10.2478/v10050-008-0054-6

\title{
ANY CHANGE IN THE METHODOLOGY \\ OF FIELD STUDIES ON BIRD MIGRATION? \\ A COMPARISON OF METHODS USED IN 1994-2003 \\ AND A QUARTER CENTURY EARLIER
}

\author{
Jarosław K. Nowakowski, Jacek Chruściel, \\ Małgorzata Ginter and Katarzyna Rosińska
}

\begin{abstract}
Nowakowski J.K., Chruściel J., Ginter M., Rosińska K. 2009. Any change in the methodology of field studies on bird migration? A comparison of methods used in 1994-2003 and a quarter century earlier. Ring 31, 2: 71-77.

The holistic approach to the study of bird migration observed in the past decades and the huge advancement in technology should be seen in the numbers and types of methods used in field studies for this phenomenon. To check this assumption, we compared field methods used in the studies on bird migration published in international journals in 1994-2003 ( $N=570$ papers) and in 1967-1976 ( $N=394$ papers). We noted an increase in the mean number of methods per a single paper (from 1.49 in the former of these decades to 1.98 in the latter) and a change in the frequency of each method. In recent years, methods such as satellite telemetry, DNA or isotope proportions analyses have been developed. An increase in the mean number of methods as well as changes of the most frequently used methods were more apparent in journals indexed on the ISI Master Journal List in 2003 than in other current journals, where the methods were often found to be similar to those applied a quarter century earlier, which surprised us.
\end{abstract}

J.K. Nowakowski (corresponding author), J. Chruściel, M. Ginter, K. Rosińska, Bird Migration Research Station, University of Gdańsk, Przebendowo, PL-84-210 Choczewo, Poland, Email: j.k.nowakowski@gmail.com

Key words: bird migration, field methods, progress in science.

\section{INTRODUCTION}

Improvements in scientific methodology are a basic aspect of scientific progress (Boyd 1991). Gauthreaux (1996), in his article on historical perspectives on bird migration studies in 1945-1995, considered researchers' methodologies "critically important to the success of any study of migration, whether it be descriptive or experimental, in the field, or in the laboratory". The easiest way to track changes in the 
methods used for studies of bird migration is to check the methods described in published scientific papers. More than a quarter century ago, Busse and Kania (1980) presented a review of the field methods used in papers on bird migration printed in 1967-1976. They provided a representative overview of 18 European and North American ornithological journals that published scientific articles on this topic. Since then there have been enormous advances in science: new methods are applied resulting from technological advancements and the approach to analysing issues is more complex, including more sophisticated statistical procedures (Gauthreaux 1996). The prevalence of research teams with specialists from different branches of science has also fostered the use of more modern methods. To find out if this holistic approach translates into the increased use of new methods and the wider range of methods in field studies on bird migration we followed the procedure used by Busse and Kania (1980) more than a quarter century earlier.

\section{MATERIAL AND METHODS}

We reviewed 13 of the most popular ornithological journals from Europe and North America issued in 1994-2003 (nine indexed on the ISI Master Journal List in 2003 and four others, which often publish papers on bird migration; Appendix). We selected 570 original papers on bird migration (reports, papers on methods and reviews were not considered) and from each study we noted the field methods used to collect data. We did not include studies conducted on captive birds, even if the birds originated from wild populations, but did include laboratory studies such as those using DNA analysis if the examined material came from wild birds. We also excluded methods that, according to the description, were used in the field but their effects were not subsequently analysed in the manuscript. Methods were grouped in 15 categories:

1. captures in all types of traps (mist-nets, Heligoland traps and others) to describe seasonal migration dynamics, daily capture dynamics, etc. (abbreviated as CA),

2. analyses of ringing recoveries or recaptures $(\mathbf{R I})$,

3. weighing (WE),

4. determination of fat deposits (irrespective of the scale and methods used-FA),

5. measuring (length of wing, tail, tarsus, wing formula, etc. - ME),

6. moult studies (MO),

7. bird counts $(\mathbf{C F})$,

8. visual observations of passage (VI),

9. moonwatching or observations in a ceilometer beam (MC),

10. voice recording (VO),

11. studies on victims of collisions with different objects (CO),

12. radar studies (RA),

13. telemetry (TE),

14. other methods based on advanced technology and achievements in other sciences (analyses using infrared detectors; laboratory analyses of various types, including genetic tests; analyses of isotope content in tissues; analyses of blood parasites; analyses of climate effect on birds, etc. - AT).

15. orientation experiments (OR). 
The last three categories were not represented in studies published in 1967-1976. In those years, orientation experiments were conducted exclusively in laboratory conditions on birds kept in captivity for a longer time. Most current laboratory techniques were not available.

We compared the ratios of papers that used the above mentioned methods between the two periods of study. When using $2 \times 2$ tables, we applied the $\chi^{2}$-test with Yates' correction.

\section{RESULTS}

In 9 ornithological journals indexed on the ISI Master Journal List in 2003 we found 5550 scientific papers published in 1994-2003. Six percent of them described bird migration based on material collected in the field (for selection criteria see Material and methods). Only two journals, namely "Ardea" and "Journal of Ornithology", had papers on migration that comprised more than $10 \%$ of all their published articles (Appendix).

In 1994-2003, an average of nearly two (1.98; number of papers $-N=570$ ) field methods were used in each published paper. In 1967-1976 this number was 1.49 methods per paper $(N=394)$. A single paper was based on data collected with maximally 7 methods (27 years earlier it was 5 methods at most), and half of the papers (50.2\%) were still based on only one method (in 1967-1976 - 64.0\% of the studies, Fig. 1; $\left.\chi^{2}=17.4, p<0.001\right)$. Of the six field methods most often used in presenting bird migration by 2003, five were also the most popular techniques 27 years earlier. Only the so-called "advanced technology" methods (AT; Fig. 2) were novel. Methods of this AT group were found in every fourth published paper, which gives these methods the fourth rank on the list of most frequently used methods. Ringing (RI) was the most

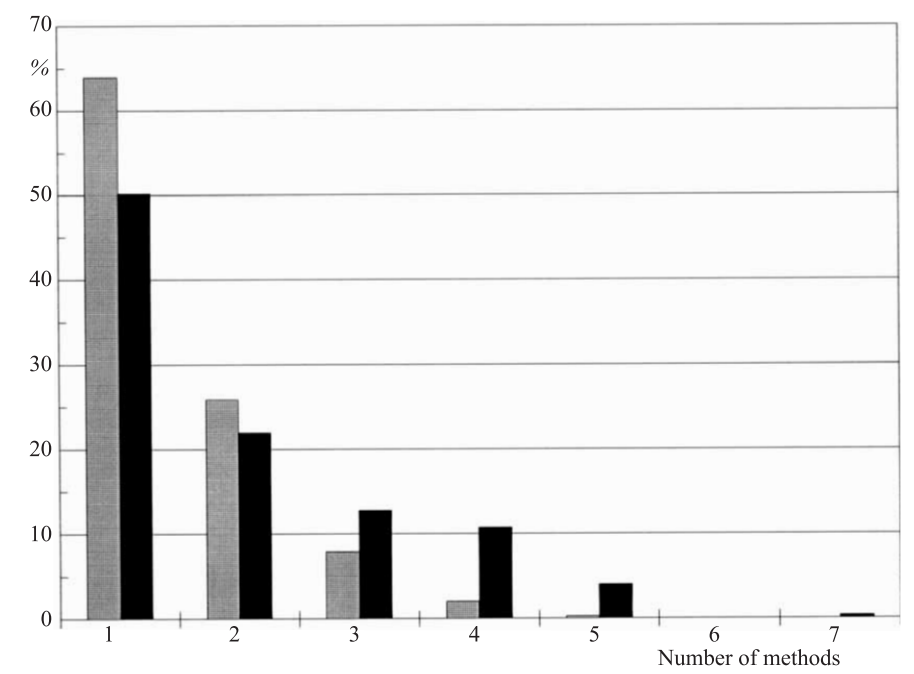

Fig. 1. The proportion of papers with different numbers of field methods used in 1967-1976 (grey bars) and in 1994-2003 (black bars). 


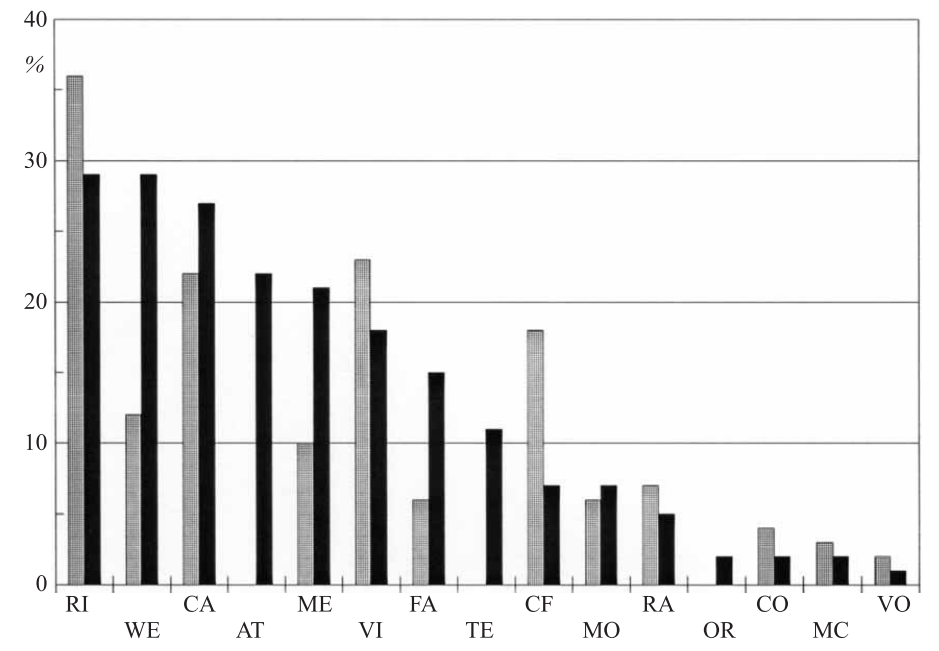

Fig. 2. The use of each field method in papers on bird migration. Grey bars - the percent of papers containing each type of method in papers published in 1967-1976, black bars - in papers published in 1994-2003: RI - recoveries or recaptures; WE - weighing; CA captures to describe dynamics; AT - advanced technology and achievements in other sciences; ME - measuring; VI - visual observations; FA - fat deposits; TE - telemetry; CF - bird counts; MO - moult studies; RA - radar studies; OR - orientation experiments; $\mathrm{CO}$ - victims of collisions; $\mathrm{MC}$ - moonwatching or observations in a ceilometer beam; $\mathrm{VO}$ - voice recording.

frequently used method, although the proportion of papers including this technique decreased significantly $\left(\chi^{2}=4.6, p=0.033\right)$. An even greater decrease (by as much as $61 \%$ ) was noted in the case of observations of feeding and resting birds (CF group $-\chi^{2}=26.6$, $p<0.001)$. On the other hand, all methods that determined the size and condition of migrating birds were used more than twice as often than a quarter century earlier (Fig. 2). The proportion of papers including analyses of body mass (based on weighing birds - WE) increased 2.3-fold - from 12 to $29 \%\left(\chi^{2}=36.5, p<0.001\right)$, which gave this method the second place in the list of the most often used techniques. Similarly, the frequency of analyses of fat deposits increased (FA, 2.4-fold increase, $\chi^{2}=17.2$, $p<0.001$ ) as well as that of linear measurements (ME, 2.2-fold increase, $\chi^{2}=21.9$, $p<0.001)$. Changes in the frequency of the remaining methods were not statistically significant.

Methods requiring expensive or advanced technology occurred relatively more frequently in journals "less interested" in papers on bird migration. The proportion of papers based on modern methods (e.g. radar - RA, telemetry - TE or advanced technology - AT) among all papers on migration published in a given journal was negatively correlated with the proportion of papers on migration in these periodicals $\left(N=13\right.$ journals, Spearman rank correlation: $\left.r_{S}=-0.66, p=0.014\right)$.

We compared the journals indexed on the ISI Master Journal List (those on this list in 1994-2003) with the remaining ones, even if they were put on the ISI List after 2003. The journals indexed on the ISI Master Journal List on average published 
papers that were based on more methods (2.1 methods/paper, $N=304)$, than others (1.8 methods/paper, $N=266$, Mann-Whitney $U$-test: $Z=3.1, p=0.002)$. There was no statistically significant difference between the indexed journals published in Europe (2.3 methods/paper, $N=144)$ and those in North America (2.0 methods/ paper, $N=160$, Mann-Whitney $U$-test: $Z=1.6, p=0.120$ ). Papers published in the journals indexed on the ISI Master Journal List differed significantly from those in the nonindexed journals also with respect to the types of methods used most often (Fig. 3). In the indexed journals, migration studies including body mass analyses (WE - 36\%), methods using advanced technology (AT - $31 \%$ papers) and analyses of linear measurements (ME - 24\%) were more common. In the remaining journals, papers were most often based on the analysis of ringing recoveries and recaptures (RI $-42 \%$ ), analyses of catches over time $(\mathrm{CA}-36 \%)$ and weighing (WE - 21\%). In general, we found methods that were expensive or requiring advanced technology (RA, TE, AT) more often in the indexed journals. The remaining periodicals were more likely to feature traditional methods, which were also most often used (two out of the three most frequently used) a quarter century earlier, namely analysis of ringing recoveries (RI) and catches (CA). Thus, in the indexed journals the migration studies based on telemetry were found 6.2 times more frequently than in the non-indexed journals, the papers featuring radar studies - 5.5 times more often and those with other hightechnology methods -2.5 times more often. In total, one or several of these methods (RA, TE, AT) were found in $52 \%$ of papers from the journals indexed on the ISI Master Journal List, but in only $15 \%$ of the other journals $\left(\chi^{2}=83.8, p<0.001\right)$.

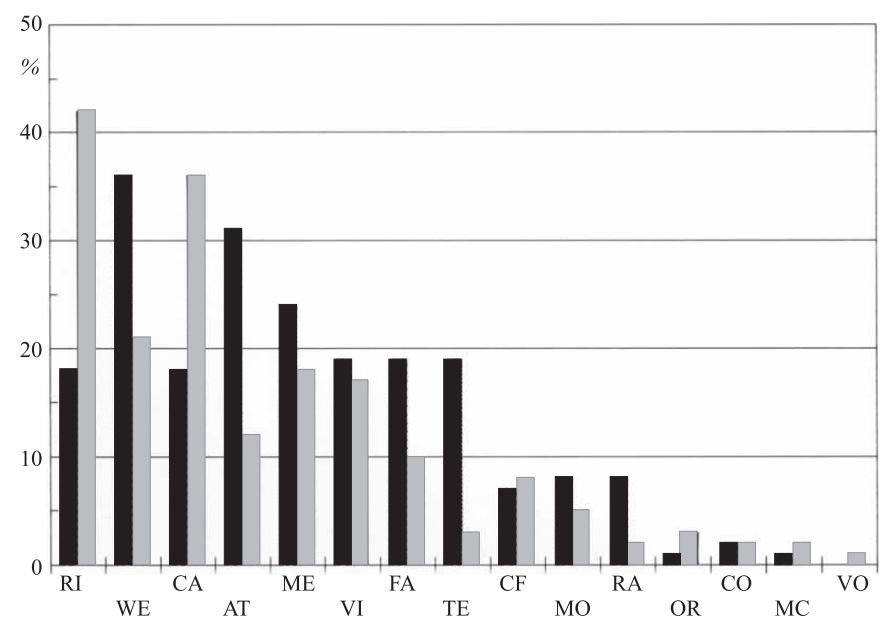

Fig. 3. Field methods used in papers published in journals indexed on the ISI Master Journal List (black bars) and non-indexed journals (grey bars). For abbreviations of methods - see Fig. 2. 


\section{DISCUSSION}

We realise that the number of field methods used to collect data analysed in a paper, and even the technical advancement of the methods, does not determine the scientific value of a study. However, it can generally be assumed that papers based on more field methods usually describe a studied phenomenon more comprehensively - especially if methods from other branches of science are also used, such as genetic analyses, analyses of stable isotopes or of climate. That is why we believe that the frequency of methods that are expensive or require advanced technology (RA, TE, AT), as well as the growing number of methods used to study such a complex phenomenon as bird migration, may reflect the development of migration studies. So, although the important discoveries are still being made with the use of the simplest methods, generally the progress of science is largely reflected in the progression of the methods used in a given field (for a discussion of the philosophy of scientific progress - see Boyd 1991, for a review of the progress in studies of bird migration between 1945 and 1995 - see Gauthreaux 1996, and for a review of studies on orientation and navigation - see Able 1995). In this light, the results we obtained are rather surprising. The average number of methods used in papers on field studies of bird migration has been increasing, pointing to a more multifaceted perspective, but still half of the papers are based on only one method.

The reason for this might be that the methods devised decades ago have often remained the most effective and none of simple methods have been abandoned (Alerstam 1993, Berthold 1993, Newton 2008). This would make the study of bird migration an interesting exception to the general pattern of scientific progress, which is a constant process of devising new methodologies to develop more theories, which are then used to produce more methods, which are used to produce more theories and so on (Boyd 1991). We rather think that this relatively small change can partially result from the pressure on scientists to establish their credentials, often manifested by requiring researchers to publish even more papers. This may lead them to try to publish as many papers as they can. Modern journals also less willingly accept long papers, consequently some of the wide and comprehensive analyses are divided, sometimes artificially, into several smaller articles.

Despite the appearance of new methods based on novel technologies, our knowledge of bird movements, especially for passerines, is still based on capturing, ringing, weighing and measuring migrant birds, methods used for the past 100 years, and on observations used from time immemorial. In our opinion, this is mainly due to three facts:

1) the belief that studies of this type neither result in measurable economic and social effects (as for instance biotechnology or genetics do) nor give any results crucial for national prestige (as e.g. space research or, again, genetics);

2) the belief that the results of studies on migrating birds can be applied only to conservation issues, and such research usually does not require very sophisticated methods; 
3) the belief that our knowledge of the course and mechanisms of migration in birds is sufficiently broad and thus no novel revolutionary discoveries and hypotheses can be expected.

One effect of these three beliefs is that government and private institutions are less likely to direct larger amounts of money to what they perceive as such "ineffective" research projects, so researchers must use inexpensive methods, rarely based on advanced technologies. This thesis is confirmed by the relatively low interest of the indexed ornithological journals in papers on bird migration, as seen in the percentage of papers they publish on this topic. Papers on migration comprised only $6 \%$ of the content of all the journals we reviewed! Migration consumes up to half the lives of many species, and the strategies they choose and bird mortality during this period crucially influence entire populations and the life history of individuals (Alerstam 1993, Berthold 1993, Newton 2008). Our knowledge of bird migration is largely incomplete and insufficient, and the state of this knowledge, or rather the lack of this knowledge, can be connected to measurable economic and social losses, as became clear in the context of avian influenza.

\section{REFERENCES}

Able K.P. 1995. Orientation and navigation: a perspective on fifty years of research. Condor 97: 592-604.

Alerstam T. 1993. Bird Migration. Cambridge Univ. Press, Cambridge.

Berthold P. 1993. Bird Migration: a general survey. Oxford Univ. Press, Oxford.

Boyd R. 1991. On the current status of scientific realism. In: Boyd R., Gasper P., Trout J.D. (Eds). The Philosophy of Science. The MIT Press.

Busse P., Kania W. 1980. Field methods in bird migration studies and ways of publishing the results. Acta orn. 17: 25-36.

Gauthreaux S.A.Jr. 1996. Bird migration: Methodologies and Major Reseach Trajectories (1945-1995). Condor 98: 442-453.

Newton I. 2008. The migration ecology of birds. Acad. Press, Oxford. 


\section{APPENDIX}

Ornithological journals considered in the present study and their characteristics: $N$ - the number of ornithological papers published in 1994-2003 (in parentheses - the number of papers on migration considered in the present paper); $\%_{\mathrm{Mig}}$ - the proportion of articles on migration among all papers published in a given journal; $a v g_{M}$ - the mean number of methods used in one paper; $M$ - the method (methods) that occurred in the highest number of papers; \% - the proportion of papers in which expensive methods or those requiring advanced technology (RA, TE, AT) were used

\begin{tabular}{|l|r|r|r|r|r|}
\hline \multicolumn{1}{|c|}{ Journal } & $N$ & $\%_{M i g}$ & avg & M & \multicolumn{1}{c|}{$\%$} \\
\hline Acta Ornithologica & $207(3)$ & 1 & 3.0 & CA, ME & 33 \\
\hline Ardea & $292(35)$ & 12 & 2.4 & RI & 43 \\
\hline Auk & $1161(47)$ & 4 & 2.3 & WE, AT & 60 \\
\hline Avian Ecology and Behaviour* & $65(32)$ & 49 & 1.5 & CA & 25 \\
\hline Condor & $1086(78)$ & 7 & 1.8 & WE & 51 \\
\hline Ibis & $806(38)$ & 5 & 2.1 & AT & 58 \\
\hline Journal of Ornithology & $340(36)$ & 11 & 1.7 & AT & 44 \\
\hline Journal of Avian Biology & $588(57)$ & 10 & 2.2 & WE & 67 \\
\hline Ornis Fennnica & $222(14)$ & 6 & 2.6 & CA & 21 \\
\hline Ringing and Migration & $180(49)$ & 27 & 1.8 & RI & 4 \\
\hline The Ring & $139(77)$ & 55 & 2.1 & CA & 14 \\
\hline Vogelwarte & $176(69)$ & 39 & 1.7 & RI & 3 \\
\hline Wilson Bulletin & $848(35)$ & 4 & 2.1 & CA & 34 \\
\hline
\end{tabular}

* journal published since 1998 